\title{
King George Island ice cap geometry updated with airborne GPR measurements
}

\author{
M. Rückamp ${ }^{1, *}$ and N. Blindow ${ }^{2}$ \\ ${ }^{1}$ Institute of Geophysics, University of Hamburg, Bundesstraße 55, 20146 Hamburg, Germany \\ ${ }^{2}$ Federal Institute for Geosciences and Natural Resources, Stilleweg 2, 30655 Hannover, Germany \\ * formerly at: Institute of Geophysics, University of Münster, Corrensstraße 24, 48149 Münster, Germany
}

Correspondence to: M. Rückamp (martin.rueckamp@zmaw.de)

Received: 15 November 2011 - Published in Earth Syst. Sci. Data Discuss.: 8 December 2011

Revised: 18 June 2012 - Accepted: 22 June 2012 - Published: 24 July 2012

\begin{abstract}
Ice geometry is a mandatory requirement for numerical modelling purposes. In this paper we present a consistent data set for the ice thickness, the bedrock topography and the ice surface topography of the King George Island ice cap (Arctowski icefield and the adjacent central part). The new data set is composed of ground based and airborne ground penetrating radar (GPR) and differential GPS (DGPS) measurements, obtained during several field campaigns. Blindow et al. (2010) already provided a comprehensive overview of the ground based measurements carried out in the safely accessible area of the ice cap. The updated data set incorporates airborne measurements in the heavily crevassed coastal areas. Therefore, in this paper special attention is paid to the airborne measurements by addressing the instrument used, survey procedure, and data processing in more detail. In particular, the inclusion of airborne GPR measurements with the $30 \mathrm{MHz}$ BGRP30-System developed at the Institute of Geophysics (University of Münster) completes the picture of the ice geometry substantially. The compiled digital elevation model of the bedrock shows a rough, highly variable topography with pronounced valleys, ridges, and troughs. Mean ice thickness is $240 \pm 6 \mathrm{~m}$, with a maximum value of $422 \pm 10 \mathrm{~m}$ in the surveyed area. Noticeable are bounded areas in the bedrock topography below sea level where marine based ice exists. The provided data set is required as a basis for future monitoring attempts or as input for numerical modelling experiments. The data set is available from the PANGAEA database at doi:10.1594/PANGAEA.770567.
\end{abstract}

\section{Introduction}

King George Island (KGI) has an area of $1250 \mathrm{~km}^{2}$ (Simões et al., 1999) is the largest of the South Shetland Islands (SSI) situated at the northern tip of the Antarctic Peninsula (Fig. 1). Due to their small size and geographical location in maritime climate conditions, the ice caps of the SSI are regarded as mostly temperate (ice temperatures at or close to pressure melting point conditions); meltwater may be present within the ice body (Paterson, 1994). A polythermal structure has been suggested for the ablation areas of some of their glaciers and ice caps (Wen et al., 1998; Navarro et al., 2009; Blindow et al., 2010). More than $90 \%$ of the KGI is glaciated and the main ice domes rise up to $700 \mathrm{~m}$ (all heights are given in WGS84 ellipsoidal heights (m), if not stated other- wise; e.g. orthometric heights ( $m$ a.s.l.) are calculated considering a constant offset of $21 \mathrm{~m}$ using the EGM 2008 model, where the WGS84 ellipsoidal height is above the orthometric height, Pavlis et al., 2008). Blindow et al. (2010) provided the most detailed picture so far of the ice surface and the bedrock topography as well as the ice thickness distribution of the KGI ice cap. There were some earlier echo-sounding works on KGI, though with limited coverage and sometimes ambiguous results. References to these earlier works can be found in Blindow et al. (2010). In the study of Blindow et al. (2010), the geometry information was derived from ground based ground penetrating radar (GPR) and differential GPS (DGPS) profile measurements in the safely accessible uncrevassed areas. The GPR measurements were carried 


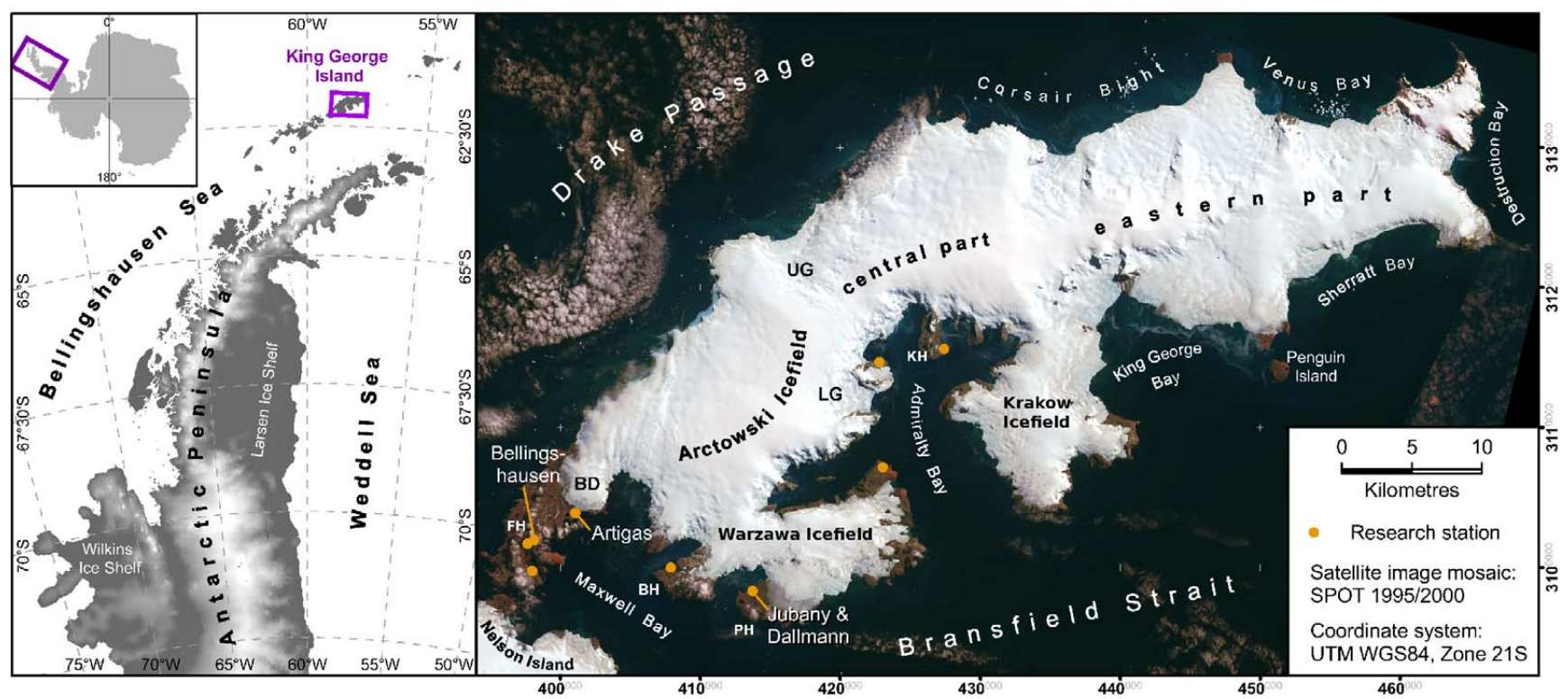

Figure 1. Overview map of King George Island and its location on the Antarctic Peninsula. FH denotes Fildes Peninsula, BH Barton Peninsula, PH Potter Peninsula, KH Keller Peninsula, BD Bellingshausen Dome, LG Lange Glacier, and UG Usher Glacier. Background Image is a (C) SPOT Image from 2000. Reprinted from the Annals of Glaciology with permission of the International Glaciological Society.

out during austral summers 1997/98 and 2006/07. The GPR equipment used was a proprietary construction of the University of Münster (Germany). It was successfully operated at centre frequencies of $25 \mathrm{MHz}$ and $50 \mathrm{MHz}$ with the aim of detecting the bedrock topography at this ice cap. The choice for low frequency GPR Systems was made to overcome scattering effects and absorption of temperate ice (e.g. Smith and Evans, 1972). However, the work lacks in coverage of the heavily crevassed coastal areas.

During a field campaign in austral summer 2008/09, we applied an airborne GPR system in the northwestern coastal areas to achieve a more complete picture of the ice geometry. This paper describes the airborne GPR system we used, the airborne GPR survey as well as the corresponding data processing. These data are integrated into the already existing data set from Blindow et al. (2010) in order to provide consistent digital elevation models (DEM) for the ice geometry of the KGI ice cap.

\section{Methods}

\subsection{GPR system}

An airborne GPR system was used to measure ice thickness in inaccessible, crevassed coastal areas of the ice cap. This $30 \mathrm{MHz}$ impulse system was developed at the University of Münster (Germany) and was named UMAIR (University of Münster Airborne Ice Radar) until the end of 2009. The system was then purchased by BGR (Federal Institute for Geosciences and Natural Resources, Germany) and is now operating as BGR-P30 in geological and glaciological projects.
The radar consists of a shielded broadband antenna system with integrated electronics for downward transmission of the $30 \mathrm{MHz}$ wavelet and reception of upgoing reflected waves. At the receiving antenna, the signals are directly A/D converted at a rate of $400 \mathrm{MHz}$ with 4096 points per trace, 256fold stacked and then routed via fibre optic cables to the control unit in the helicopter cabin. At $10 \mathrm{~Hz}$ data acquisition rate and $35 \mathrm{kn}$ average helicopter cruising speed, $\sim 500$ traces per kilometre are recorded. For more details about the radar system BGR-P30 see Blindow (2009), Eisenburger et al. (2009), and Blindow et al. (2011).

\subsection{GPR survey}

Figure 2 shows the spatial distribution and temporal coverage of the ground based GPR profiles and the airborne GPR profiles. As shown in Blindow et al. (2010), the ground based survey with a length of about $1200 \mathrm{~km}$ covered an area of $\sim 200 \mathrm{~km}^{2}$ of the Arctowski icefield, the adjacent central part, and the exposed located Bellingshausen Dome. At the Arctowski icefield the grid was orientated in northwestsoutheast intersecting direction with a grid spacing of $1000 \mathrm{~m}$ between neighbouring profiles; on the central part the survey was arranged in north-south intersecting direction with a spacing of $500 \mathrm{~m}$. These grids were designed to have a large number of crossover check points.

For the northwestern areas of the Arctowski icefield and the central part, the total airborne GPR survey length was $250 \mathrm{~km}$ with an estimated coverage of $140 \mathrm{~km}^{2}$. The grid spacing between the northwest-southeast orientated profiles was $\sim 700 \mathrm{~m}$. The airborne flight lines were designed in 


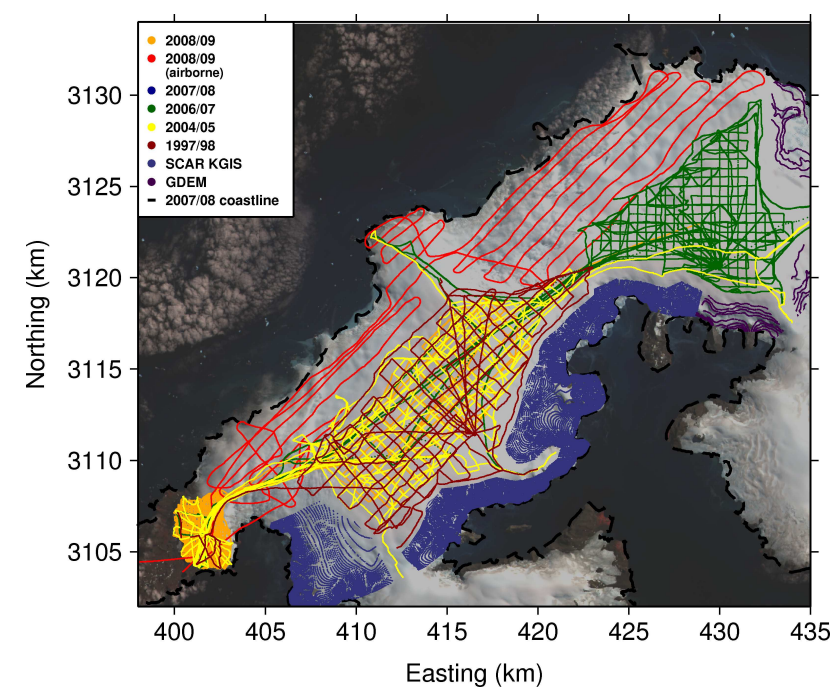

(a)

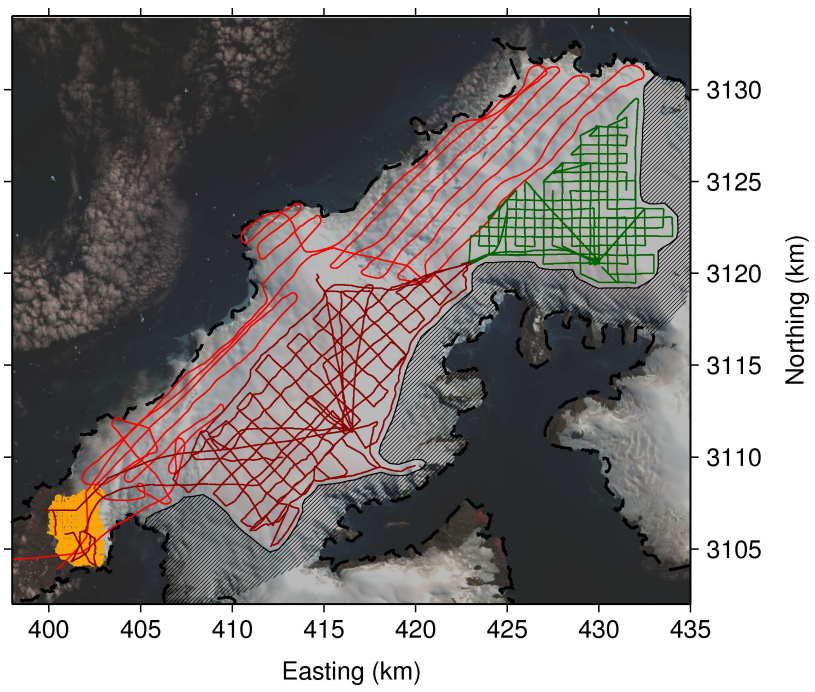

(b)

Figure 2. Spatial distribution and temporal coverage of the (a) DGPS and (b) GPR profiles in the various campaigns and additional data sets. The shaded area indicates where the DEM's are based on extrapolation. Background image is a (C) SPOT Image from 2000.

order to connect continuously to the ground based GPR survey. The flight was realised with a Sikorsky UH-60 Black Hawk utility helicopter with the GPR antenna as hanging load (the helicopter was provided by FACH - Fuerza Aérea de Chile). The Black Hawk was equipped with fuel tanks which allowed to perform the flight without a refuelling stop. The GPR survey consisted of 53 profile sections achieved by one flight taking four hours. The average cruising speed was $35 \mathrm{kn}\left(65 \mathrm{~km} \mathrm{~h}^{-1}\right)$ at $40 \mathrm{~m}$ average elevation of the antenna over the ground (controlled by laser altimeter). The radar profiles were located with a pair of NovAtel DLV dual frequency DGPS receivers collecting position data $(x, y, z)$ at a sampling rate of $10 \mathrm{~Hz}$. However, due to bad weather conditions, and therefore flight hour limitations, there were only a few crossover check points within the airborne survey as well as a limited overlap between the airborne and ground based grids.

\subsection{GPR processing and data}

All airborne radar data were processed with the ReflexW program (Ver. 4.5, K.J. Sandmeier software) in several steps comprising georeferencing, a time zero correction corresponding to the antenna offset, consideration of the air layer, and a frequency domain Butterworth-Bandpass filter. The actual spectral maximum of the BGR-P30 system is at $25 \mathrm{MHz}$ (corresponding to wavelengths of $6.7 \mathrm{~m}$ in ice and $12 \mathrm{~m}$ in air), the bandwidth is approx. $20 \mathrm{MHz}$. The spectral content of thin-layer reflections and point diffractions is slightly shifted towards higher frequencies. To suppress these and to emphasise the bedrock reflections a filter setting of 5 to $30 \mathrm{MHz}$ is appropriate. Time domain migration (diffraction stack) with a two layer velocity model was used to collapse diffraction hyperbolas and to recover the dip of reflectors. The two layer velocity model consisted of the air layer with a radio-wave velocity (RWV) of $0.3 \mathrm{~m} \mathrm{~ns}^{-1}$ and the ice layer with an average RWV of $0.168 \mathrm{~m} \mathrm{~ns}^{-1}$. To account for dielectric losses in the temperate ice a gain of $0.08 \mathrm{dBm}^{-1}$ was applied to all traces.

The ice surface elevation ${ }^{1} z_{\mathrm{s}}$ was obtained by subtracting the thickness of the air layer, derived from the airborne GPR surface reflection, from the measured DGPS height at the GPR antenna. Ice thickness values $H$ were determined by converting the two-way traveltimes (twt in ns) with an appropriate depth-dependent RWV model. We used the common mid point (CMP) measurements reported in Blindow et al. (2010) to determine the velocities of the radar signals in the subsurface. These measurements revealed a two-layer model with a RWV in the firn layer of $0.194 \mathrm{~m} \mathrm{~ns}^{-1}$ and a RWV of $0.168 \mathrm{mns}^{-1}$ in the ice. These values are consistent with earlier measurements performed by Travassos and Simões (2004) on KGI and by Navarro et al. (2009) on Hurd Peninsula Ice Cap, Livingston Island. Additionally, we introduce a firn correction term to account for the spatially variable firn layer,

$H=H_{\text {firn }}+0.168\left[\mathrm{~m} \mathrm{~ns}^{-1}\right]\left(t_{\mathrm{b}}-t_{\text {firn }}\right) / 2$

with the empirical firn correction term

$H_{\text {firn }}= \begin{cases}42 \log \left(0.004 z_{\mathrm{s}}\right) & 250 \leq z_{\mathrm{s}} \leq 700 \mathrm{~m} \text { a.s.l. } \\ 0.0 & z_{\mathrm{s}}<250 \mathrm{~m} \text { a.s.1., }\end{cases}$

where $t_{\text {firn }}$ and $t_{\mathrm{b}}$ are the twts of the firn and bedrock reflections, respectively. $H_{\text {firn }}$ is the thickness of the firn layer

\footnotetext{
${ }^{1}$ Ice surface elevation is in the accumulation area relative the snow surface, in the ablation area relative the ice surface.
} 


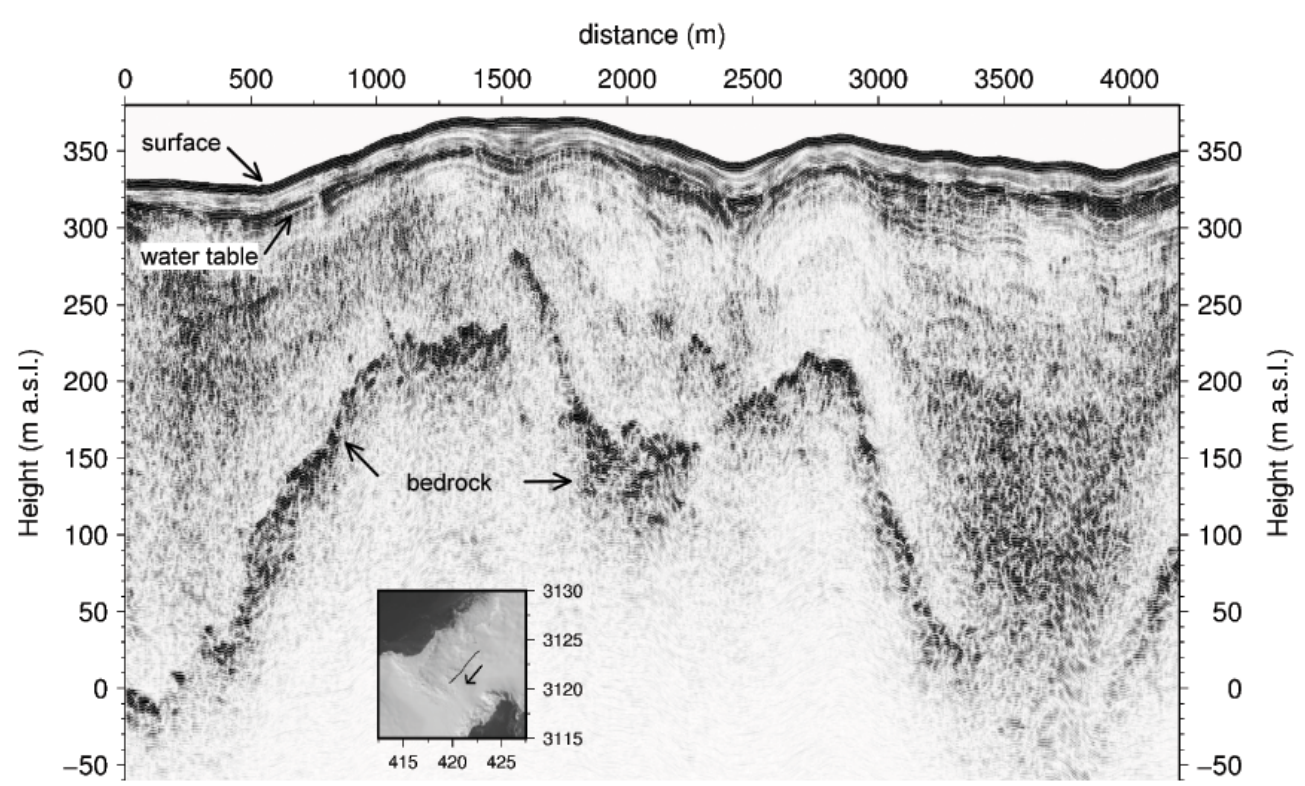

Figure 3. Typical example of an airborne radargram. The inset shows the profile location and flight direction. Surface, water table (depth between $20 \mathrm{~m}$ and $30 \mathrm{~m}$ ) and bedrock reflections are marked.

with the unit $\mathrm{m}$. The firn correction represents a logarithmic adaption to the spatially extended water table with varying depth marking the firn ice transition zone in the accumulation area (Blindow et al., 2010). The fitted relationship is forced to be continuous at $z_{\mathrm{s}}=250 \mathrm{~m}$ a.s.l. Assuming a RWV in the firn layer of $0.194 \mathrm{~m} \mathrm{~ns}^{-1}$, our GPR measurements detected the water table at a maximum depth of $40 \mathrm{~m}$ at $700 \mathrm{~m}$ a.s.1. elevation and around $25 \mathrm{~m}$ depth at $400 \mathrm{~m}$ a.s.1. Below $\sim 250$ m a.s.l., the water table disappears. Note, that the applied fit slightly overestimate/underestimate the true values (up to $5 \mathrm{~m}$ ). The latter value represents the equilibrium line altitude (e.g. Braun and Rau, 2000). The firn ice transition zone at the higher altitudes was previously identified by Wen et al. (1994) and Simões et al. (2004). They obtained water table depths by drilling at the Arctowski icefield around $650 \mathrm{~m}$ a.s.l. elevation. Our water table depth of $40 \mathrm{~m}$ at $700 \mathrm{~m}$ a.s.l. elevation coincides with their measurements.

An example of a processed and topographically corrected airborne radar-data obtained in the transition zone from the Arctowski icefield to the central part can be seen in Fig. 3 . The profile shows the water table, the bedrock and internal scattering. The ice surface is smooth whereas the bedrock is rough with carved valleys.

Before merging the different data sets collected during several expeditions in order to generate the DEMs, we have to mention that the ice cap is not in balance (Rückamp et al., 2011). This requires consideration of surface differences between different acquisition years.

The analysis in Rückamp et al. (2011) aimed to derive surface changes in the eleven year period by comparing the 1997/98 data successively with the 2004/05, 2006/07,
2007/08 and 2008/09 DGPS data at the crosspoints of the profiles. From the analysis that follows, the ice cap above $250 \mathrm{~m}$ a.s.l. is in balance. At Bellingshausen Dome below $250 \mathrm{~m}$ a.s.l., significant height changes have been measured in the eleven year period (up to $1.44 \mathrm{~m} \mathrm{a}^{-1}$ at $20 \mathrm{ma}$ a.s.l.). As we surveyed Bellingshausen Dome on a very dense grid in the 2008/09 austral summer (Rückamp et al., 2011), we simply dropped measurements from former expeditions. All other low elevation areas (margins of the ice cap) were measured in a single airborne survey in the 2008/09 austral summer as well. Obviously, measurements in areas above $250 \mathrm{~m}$ a.s.l. do not require corrections in case of multiple readings in different acquisition years. In these area's surface heights, hence ice thickness, do not show changes within a decade. Therefore, the compiled data set refers to the 2008/09 austral summer. Note that a direct conclusion of changing ice thickness within the eleven year period using the crosspoint analysis is not possible. As the GPR surveys are performed in three different campaigns with a poor overlap, the crosspoint analysis is not applicable (ground based survey in 1997/98 at Arctowski icefield and 2006/07 at the central part; airborne survey in 2008/09 at the coastal parts; see Fig. 2b).

In the following, we provide vertical error estimates for the original data (i.e. DGPS heights and ice thickness) along the tracks. To make sure, that the data are not influenced by inter-annual variations, comparative ice surface heights and ice thickness are calculated for each individual survey collected in a campaign. Furthermore, we aimed to provide accuracies for both, the airborne and the ground based survey separately. To do so, comparative values at each crossover 
Table 1. Vertical accuracy of the grids (ice surface and ice thickness) and regional variations. The difference between gridded and original data is calculated by subtracting the grid value from the original value.

\begin{tabular}{lrr}
\hline Region & $\begin{array}{c}\text { ice surface } \\
\text { mean difference }(\mathrm{m})\end{array}$ \\
\hline whole ice cap & 0.00 & 0.53 \\
Bellingshausen Dome & -0.45 & 0.71 \\
Arctowski icefield & 0.95 & -0.66 \\
Central part & -0.11 & 0.51 \\
northwestern coastal part & -0.40 & 0.24 \\
\hline
\end{tabular}

check points were calculated using the same crosspoint analysis tool described in Rückamp et al. (2011).

The crosspoint analysis performed for the ice surface topography of the ground based measurements reveals, that almost all checkpoints (a few thousands of crossover checkpoints) show absolute differences below $0.5 \mathrm{~m}$. The cumulative distribution depicts that $98 \%$ of vertical errors are less than $6 \mathrm{~cm}$. However, some points of comparison, located at the glaciated margins (Bellingshausen Dome), show differences in metre range. These differences are attributed to melt processes as the season progresses and to larger topographic gradients. For the airborne measurements with less crossover check points (a few hundred), the analysis revealed that $63 \%$ of vertical errors are less than $1 \mathrm{~m}$ where the maximum difference is $3 \mathrm{~m}$. This poorer accuracy is attributed to the rough (heavily crevassed) surface. In this area, large vertical steps occur over short horizontal distances.

Vertical accuracy of comparative ice thickness (a few thousand) derived by ground based measurements are in a range of a few metres or less. This is lower than half the wavelength in ice $\lambda / 2(\lambda / 2$ gives a rough estimate of the vertical resolution of the GPR). In our case (25 MHz GPR) $\lambda / 2$ is approx. $3.4 \mathrm{~m}$ considering a RWV in ice of $0.168 \mathrm{~m} \mathrm{~ns}^{-1}$. From this analysis we calculated a mean vertical accuracy of $\pm 5.4 \mathrm{~m}$. With a mean ice thickness of $250 \mathrm{~m}$, we provide a relative error for $H$ of $\pm 2.1 \%$.

For the airborne survey only 20 comparative ice thickness values are found by the crosspoint analysis. This is attributed to the design of the airborne survey and missing bedrock reflections. The mean value is approx. $\pm 4 \mathrm{~m}$ (approx. $\lambda / 2$ ) while the maximum value is $6.4 \mathrm{~m}$. The calculated mean ice thickness along the airborne profiles is $150 \mathrm{~m}$ and the relative error of $H$ is then $\pm 2.6 \%$.

After merging the data sets, we included two already existing ice surface topography data sets for the Admiralty Bay area available via SCAR KGIS (Braun et al., 2001) and the ASTER-GDEM homepage (http://asterweb.jpl.nasa.gov/ gdem.asp) (Fig. 2a). The latter is smoothed to suppress noise. Furthermore, we added the coastline (taken from Rückamp et al., 2011) with values of $0 \mathrm{~m}$ for the ice thickness/ice cliff height except for the airborne surveyed areas. The spatially

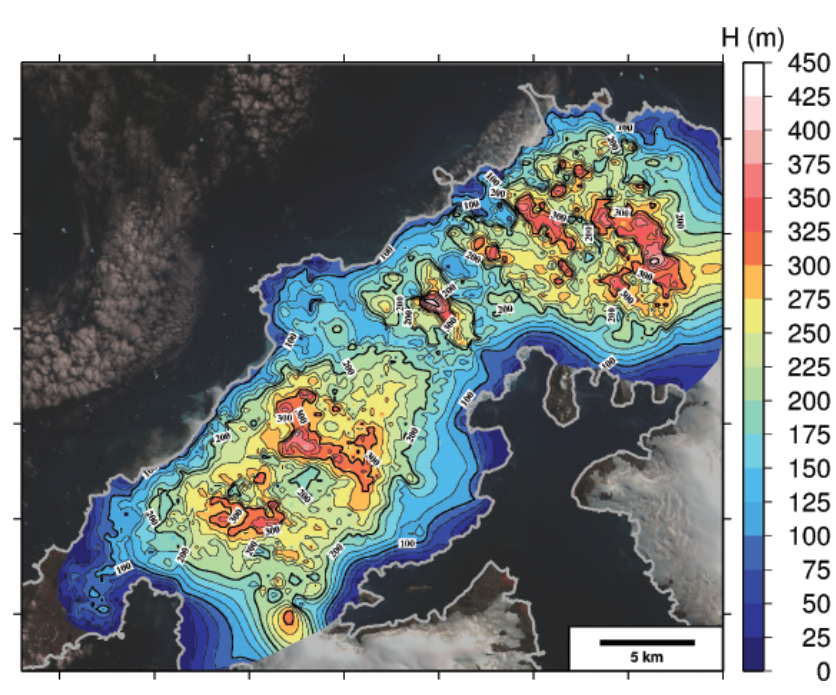

Figure 4. Interpolated ice thickness distribution $H$ in $\mathrm{m}$ on King George Island (the contour line interval is $25 \mathrm{~m}$ ). The grey thick line shows the coastline. Database: compilation of the ground based survey (taken from Blindow et al., 2010) and the airborne measurements. Background image is a (C) SPOT Image from 2000.

unstructured data set along the profiles was then gridded using the kriging algorithm on a $250 \mathrm{~m}$ grid for the ice surface topography $z_{\mathrm{s}}$ and ice thickness $H$. Subtracting the ice thickness grid from the ice surface grid, we obtain a grid for the bedrock topography $z_{\mathrm{b}}$. With these data sets, we constructed DEMs for the ice surface and bedrock topography as well as a map of the ice thickness distribution.

The accuracy check of the original data performed above does not tell us anything about the accuracy of the grids and their spatial variations in error across the grid. Therefore, we will firstly calculate the mean vertical differences from the grids to the whole original data set (thickness soundings) by applying a bi-linear interpolation on the gridded data. Secondly, to quantify errors in different parts of the grids, the mean vertical difference is calculated for the Bellingshausen Dome, for the Arctowski icefield, for the central part, and for the airborne survey in the coastal parts. The calculated values are listed in Table 1. A negative (positive) sign represents a larger (smaller) grid value than the original data. It is quite remarkable that vertical errors of the grids are less than $\pm 1 \mathrm{~m}$.

\section{Results}

\subsection{Ice thickness map}

Figure 4 shows the interpolated ice thickness distribution $H$ (m) in the investigated area. The maximum ice thickness on the profiles is $422 \pm 10 \mathrm{~m}$ measured at the central part; at Arctowski icefield the maximum value is $397 \pm 9 \mathrm{~m}$. These listed values remained unchanged compared to Blindow et al. (2010), whereas the newly calculated mean ice thickness 


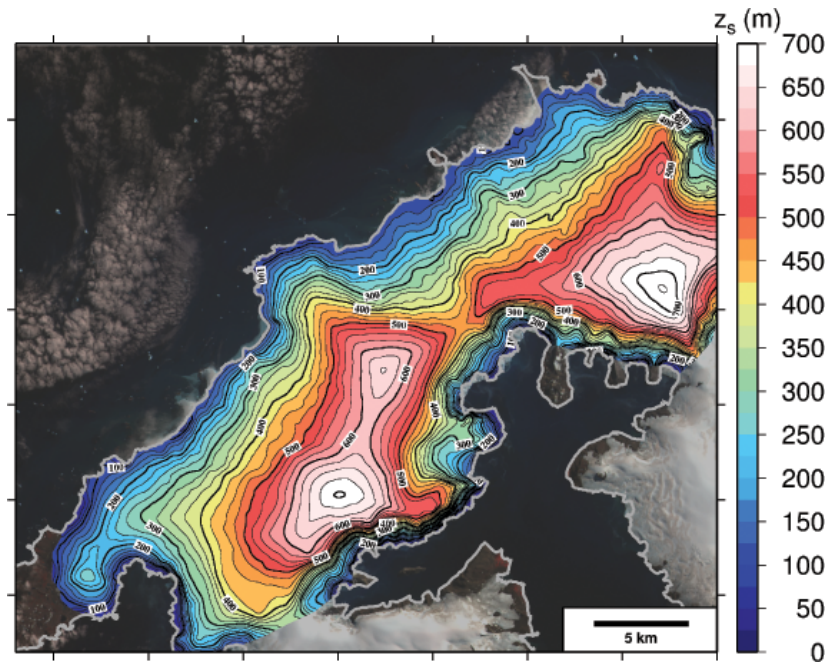

Figure 5. DEM of the interpolated ice surface topography $z_{\mathrm{s}}$ in m (WGS84 ellipsoidal height) on King George Island (the contour line interval is $25 \mathrm{~m}$ ). The grey thick line shows the coastline. Database: compilation of the ground based survey (taken from Blindow et al., 2010) and the airborne measurements. Background image is a C SPOT Image from 2000.

along the profiles with $238 \pm 5 \mathrm{~m}$ is slightly lower. This reduced value is explained by the generally lower ice thickness values in the coastal areas compared to the inner parts. However, along the airborne profiles we found a maximum ice thickness value of $412 \pm 9 \mathrm{~m}$ located in the transition zone from the Arctowski icefield to the central part. Using the interpolated grids, the ice volume of the investigated area was calculated to be $88.2 \pm 3.3 \mathrm{~km}^{3}$ over an area of $465 \pm 10 \mathrm{~km}^{2}$. As mentioned by Blindow et al. (2010), some southeast to northwest striking areas of thick ice are clearly visible and indicate the main drainage valleys of the ice cap. These features are particularly evident in the airborne surveyed area of the central part, they can also be seen in the bedrock topography (see paragraph below). The smooth contours, e.g. near the Admiralty Bay coast, are an extrapolation artefact (Fig. 2b).

\subsection{DEM of the surface topography}

The DEM of the interpolated ice surface topography $z_{\mathrm{s}}$ is shown in the Fig. 5. Compared to Blindow et al. (2010), the main pattern of the ice surface topography remained unchanged: The Arctowski icefield shows the dominating two domes with maximum heights of $702 \mathrm{~m}$ and $650 \mathrm{~m}$; the highest elevation of $727 \mathrm{~m}$ is reached at a dome lying in the central part. The exposed located Bellingshausen Dome reveals a height at the summit of $265 \mathrm{~m}$. The airborne measurements reveal some structures in the coastal ice surface topography, e.g. a distinct ridge (interpreted as ice divide) in the central part in southeast-northwesterly direction.

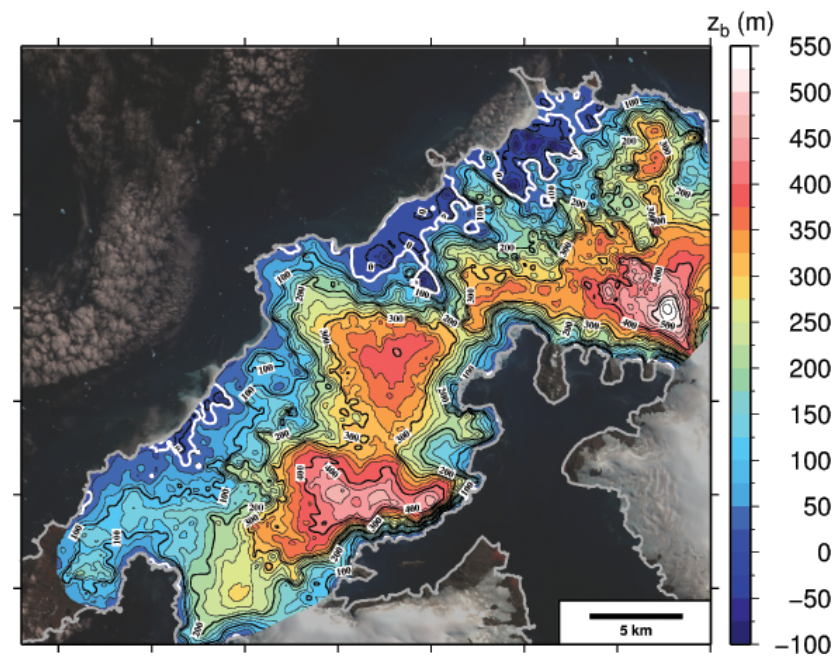

Figure 6. DEM of the calculated bedrock topography $z_{\mathrm{b}}$ in $\mathrm{m}$ (WGS84 ellipsoidal height) on King George Island (the contour line interval is $25 \mathrm{~m}$ ). The white thick line surrounds areas below sea level (details see main text); the grey thick line shows the coastline. Database: compilation of the ground based survey (taken from Blindow et al., 2010) and the airborne measurements. Background image is a (C) SPOT Image from 2000.

\subsection{DEM of the bedrock topography}

The calculated DEM of the bedrock topography is displayed in Fig. 6. Following the description of Blindow et al. (2010), the bedrock topography reflects the geological situation described in Birkenmajer (1997): an uplifted unit called Barton Horst and a lower area named Fildes Block. In the updated picture that situation is clearly apparent.

The highly variable bedrock topography reflects steep valleys pointing northwestwards. Spatially, this valleys correlate with areas of maximum ice thickness. The already mentioned, pronounced ridge in the ice surface topography at the central part is also quite evident in the bedrock topography. This ridge may divide the central part into different catchments.

Another important feature is detected by the airborne measurements: considering a constant offset of $21 \mathrm{~m}$ between the WGS84 ellipsoidal height and the orthometric height (using the EGM 2008 model, where the WGS84 ellipsoidal height is above the orthometric height, Pavlis et al., 2008), distinctive areas below the current sea level appear in the bedrock topography. These areas are visualised in Fig. 6 (white thin line). Especially the central part exhibits large areas below sea level with a maximum depth of $91 \mathrm{~m}$.

\section{Conclusions}

We provide a consistent ice geometry data set for the King George Island ice cap. The already existing picture derived from ground based GPR was updated with an airborne GPR 
survey filling the data gaps, especially close to the crevassed coastal areas. However, the presented work still lacks measurements for the eastern part of the island. This can be overcome by additional flights. Due to steep surface slopes, larger crevassed areas, and a more difficult approach from a research station, ground based measurements are much more expensive at this part of the island. Additionally, this work demonstrates impressively that GPR measurements by helicopter (with the BGR-P30-System) are a fast and an efficient tool for mapping, in particular in crevassed areas.

The available data set may be used for/as

- reference for future monitoring and for long-term measurements to detect a response of the glacier to changing climate. Glacier thinning and retreat of calving fronts at the glaciated margins are already evident and linked to the observed regional warming (Simões et al., 1999; Rückamp et al., 2011);

- including these ice volume measurements in the World Glacier Inventory (WGI) of Glaciers and Ice Caps (GIC). The need of these measures were emphasised by, for example, Radić and Hock (2010) to reduce uncertainties as these regions are poorly inventoried;

- numerical modelling studies, either diagnostic or prognostic, to enhance the knowledge of the current and future glacial state of this ice cap (e.g. Rückamp et al., 2010).

Acknowledgements. We thank the reviewers O. Brandt and F. Navarro for their helpful comments which improved this manuscript substantially. The airborne measurements would have never been possible without the particular efforts and support by FACH (Fuerza Aérea de Chile), especially by C. Madina (Comandante de Frei). The authors would like to thank the German, Chilean, and Uruguayan Antarctic Programs for their logistic support. The crew of Artigas station provided a warm and pleasant environment during the fieldwork. The SCAR KGIS and ASTERGDEM data sets are kindly provided by M. Braun (University of Erlangen). The collaboration and fieldwork with S. Suckro (AWI Bremerhaven, Germany) and B. Boemer, H. Knese, S. Ueding, (University of Münster, Germany) is kindly acknowledged. The German Research Foundation funded this study under grant BL307-1/2.

Edited by: O. Eisen

\section{References}

Birkenmajer, K.: Geology of the northern coast of King George Island, South Shetland Islands (West Antarctica), Stud. Geol. Polon., 110, 7-26, 1997.

Blindow, N.: The University of Münster Airborne Ice Radar (UMAIR): Instrumentation and first results of temperate and polythermal glaciers, Proc. 5th International Workshop on Advanced Ground Penetrating Radar, Granada, Spain, 28-30, 2009.
Blindow, N., Suckro, S., Rückamp, M., Braun, M., Schindler, M., Breuer, B., Saurer, H., Simões, J. C., and Lange, M.: Geometry and status of the King George Island ice cap (South Shetland Islands, Antarctica), Ann. Glaciol., 51, 103-109, 2010.

Blindow, N., Salat, C., Gundelach, V., Buschmann, U., and Kahnt, W.: Performance and calibration of the helicopter GPR system BGR-P30, Proceedings of the 6th International Workshop on Advanced Ground Penetrating Radar (IWAGPR 2011), Aachen, Germany, 153, 1-5, 2011.

Braun, B., Simões, J. C., Vogt, S., Bremer, U. F., Pfender, M., Saurer, H., Aquino, F. E., and Ferron, F. A.: An improved topographic database for King George Island: compilation, application and outlook., Antarct. Sci., 13, 41-52, doi:10.1017/S0954102001000074, 2001.

Braun, M. and Rau, F.: Using a multi-year data archive of ERS SAR Imagery for the monitoring of firn line positions and ablation patterns on the George Island Ice Cap (Antarctica), Dresden FRG, 2000.

Eisenburger, D., Blindow, N., Suckro, S., Lentz, H., Krellmann, Y., and Triltzsch, G.: Helicopter borne GPR systems for geological applications: pulse radar and stepped frequency radar in gating mode, Proceedings of the 5th International Workshop on Advanced Ground Penetrating Radar (IWAGPR 2009), Granada, Spain, 83-87, 2009.

Navarro, F. J., Otero, J., Macheret, Y. Y., Vasilenko, E. V., Lapazaran, J. J., Ahlstrøm, A. P., and Machio, F.: Radioglaciological studies on Hurd Peninsula glaciers, Livingston Island, Antarctica, Ann. Glaciol., 50, 17-24, 2009.

Paterson, W. S. B.: The Physics of Glaciers, Pergamon Press, Oxford, England, 3rd Edn., 1994.

Pavlis, N. K., Holmes, S. A., Kenyon, S. C., and Factor, J. K.: An Earth Gravitational Model to Degree 2160: EGM2008. European Geosciences Union General Assembly, Vienna, Austria, 13-18 April 2008, 2008.

Radić, V. and Hock, R.: Regional and global volumes of glaciers derived from statistical upscaling of glacier inventory data, J. Geophys. Res., 115, F01010, doi:10.1029/2009JF001373, 2010.

Rückamp, M., Blindow, N., Suckro, S., Braun, M., and Humbert, A.: Dynamics of the ice cap on King George Island, Antarctica: Field measurements and numerical simulations, Ann. Glaciol., 51, 80-90, 2010.

Rückamp, M., Braun, M., Suckro, S., and Blindow, N.: Observed glacial changes on the King George Island ice cap, Antarctica, in the last decade, Global Planet. Change, 79, 99-109, doi:10.1016/j.gloplacha.2011.06.009, 2011.

Simões, J. C., Bremer, U. F., Aquino, F. E., and Ferron, F. A.: Morphology and variations of glacial drainage basins in the King George Island ice field, Antarctica, Ann. Glaciol., 29, 220-224, 1999.

Simões, J. C., Ferron, F. A., Bernardo, R. T., Aristarain, A. J., Stiévenard, M., Pourchet, M., and Delmas, R. J.: Ice core study from the King George Island, South Shetlands, Antarctica, Pesquisa Antártica Brasileira, 4, 9-23, 2004.

Smith, B. M. E. and Evans, S.: Radio-echo sounding: absorption and scattering by water inclusions and ice lenses, J. Glaciol., 11, 133-146, 1972.

Travassos, J. and Simões, J. C.: High-resolution radar mapping of internal layers of a subpolar ice cap, King George Island, Antarctica, Pesquisa Antártica Brasileira, 4, 57-65, 2004. 
Wen, J., Kang, J., Xie, Z., Han, J., and Lluberas, A.: Climate, mass balance and glacial changes on small dome of Collins ice cap, King George Island, Antarctica, Antarct. Res., 5, 52-61, 1994.
Wen, J., Kang, J., Han, J., Xie, Z., Liu, L., and Wang, D.: Glaciological studies on King George Island ice cap, South Shetland Islands, Antarctica, Ann. Glaciol., 27, 105-109, 1998. 